\title{
Digestibilidade Aparente de Dietas Contendo Diferentes Níveis de Amido para Coelhos em Crescimento ${ }^{1}$
}

\author{
Alex Martins Varela de Arruda ${ }^{2}$, Ronaldo Dessimoni Carregal ${ }^{3}$, Renato Gonçalves Ferreira ${ }^{4}$
}

RESUMO - Com o objetivo de avaliar a influência do amido dietético sobre a digestibilidade aparente dos nutrientes, para coelhos em fase de crescimento, quatro dietas experimentais foram elaboradas de forma a conter níveis crescentes de amido de milho (23, 28, 33 e $38 \%$ de amido total na base da matéria seca (MS), os quais foram fornecidas a 20 coelhos da raça Nova Zelândia Branco, distribuídos em gaiolas de metabolismo individuais, segundo delineamento inteiramente casualizado. Os resultados obtidos demonstraram efeito linear crescente para os coeficientes de digestibilidade aparente da MS, matéria orgânica (MO), fibra em detergente neutro (FDN) e amido, à medida que aumentou o nível de amido dietético nas dietas experimentais. O nível de $38 \%$ de amido dietético proporcionou, portanto, o melhor coeficiente de digestibilidade para o amido $(87,26 \%)$. Não foram observadas diferenças para os coeficientes de digestibilidade aparente da proteína bruta (PB), energia bruta (EB) e fibra em detergente ácido (FDA), em relação aos diferentes níveis de amido nas dietas experimentais. No entanto, para o teor de extrato etéreo (EE), foi verificado melhor aproveitamento (89,46\%) para os animais alimentados com a dieta contendo $23 \%$ de amido. Os coelhos foram eficientes em digerir o amido de milho, quando este apresentou alta participação na porção carboidrato total da dieta.

Palavras-chave: amido de milho, coelhos, digestibilidade, nutrição

\section{Apparent Digestibility of Diets with Different Starch Levels for Growing Rabbits}

\begin{abstract}
With the objective to evaluate the effect of dietetic starch on the nutrients apparent digestibility for rabbits in the growing phase, four experimental diets were formulated to contain increasing corn starch levels $(23,28,33$ and $38 \%$ total starch levels in dry matter [DM] basis). A total of 20 White New Zealand rabbits were allotted to metabolism cages in a completely randomized design. The results showed a crescent linear effect for the coefficients of apparent digestibility for DM, organic matter (OM), neutral detergent fiber (NDF) and starch as the dietary starch level increased in the experimental diets. The $38 \%$ of dietary starch level presented, therefore, the best digestibility of starch $(87.26 \%)$. No differences were observed for the coefficients of apparent digestibility for crude protein (CP), gross energy (GE) and acid detergent fiber (ADF) at different starch levels. However, the best fat digestibility $(89.46 \%)$ was verified for the animals fed diet with $23 \%$ starch. The rabbits were efficient in digesting purified cornstarch, when this ingredient have a high participation in total carbohydrate fraction of the diets.
\end{abstract}

Key Words: cornstarch purified, digestibility, nutrition, rabbits

\section{Introdução}

O uso de cereais como fonte de energia em rações para coelhos é amplamente difundido, pois permite aporte energético suficiente para suprir as necessidades de mantença e produção em ritmo intensivo. No entanto, na maioria dos animais nãoruminantes, a digestão do amido de cereais depende de inúmeros fatores, como a origem botânica, no que se refere à textura do endosperma e à relação amilose/amilopectina, e o tipo de processamento do alimento, o qual pode propiciar transformações físicas benéficas sobre a digestibilidade dos grânulos de amido (DE BLAS, 1984; CHEEKE, 1987). Por outro lado, a digestibilidade da fração amilácea dos ingredientes e das dietas para coelhos, assim como o desenvolvimento da atividade amilásica pancreática em coelhos na fase de crescimento, tem sido pouco investigada. Tem-se sugerido que este potencial enzimático é baixo no momento da desmama e tende a se elevar com a idade dos animais. Dessa forma, a capacidade de digestão do amido no intestino delgado de coelhos, no período subseqüente à desmama, pode não ser suficiente para hidrolisar e disponibilizar este nutriente, tornando-o substrato para a atividade fermentativa cecal e resultando em disbiose na

\footnotetext{
1 Parte da Dissertação de Mestrado em Zootecnia do primeiro autor, financiado pelo CNPq.

2 Bolsista de Doutorado em Zootecnia/UFV, Viçosa, MG. E-mail: amvarela@alunos.ufv.br

3 Professor do Departamento de Zootecnia, FCAV - UNESP, Jaboticabal, SP.

4 Doutor em Zootecnia, FCAV - UNESP, Jaboticabal, SP.
} 
microflora intestinal (MORISSE, 1986; CHEEKE, 1989; DE BLAS, 1991; e LEBAS, 1992).

Assim, na nutrição e alimentação de coelhos, tornou-se de extrema importância o conhecimento da relação amido:fibra dietética sobre a eficiência alimentar, o rendimento produtivo e o estado sanitário. Postulada pioneiramente por CHEEKE e PATTON (1980) e revisada por GIDENNE (1996), a sobrecarga de amido cecal possivelmente é fator favorável ao desenvolvimento de uma população microbiana subdominante de clostrídios e colibacilos, capazes de causar diarréias e enterotoxemias fatais. Portanto, objetivou-se neste estudo avaliar a influência de diferentes níveis de inclusão de amido de milho sobre a digestibilidade aparente de dietas para coelhos em crescimento.

\section{Material e Métodos}

O experimento foi conduzido no Setor de Cunicultura do Departamento de Zootecnia de Ruminantes e Animais de Ceco Funcional, na Faculdade de Ciências Agrárias e Veterinárias de Jaboticabal (FCAVJ) da Universidade Estadual Paulista (UNESP).

Os tratamentos constituíram-se de dietas isocalóricas, isoprotéicas e isofibrosas, considerando-se as exigências nutricionais dos coelhos na fase de crescimento, segundo o NATIONAL RESEARCH COUNCIL - NRC (1977). As dietas experimentais foram oferecidas à vontade na forma peletizada, contendo níveis crescentes de amido de milho em substituição ao óleo de soja, fornecendo os seguintes níveis de amido total na base da matéria seca: $\mathrm{T}_{1}$ (23\%), $\mathrm{T}_{2}(28 \%), \mathrm{T}_{3}(33 \%)$ e $\mathrm{T}_{4}(38 \%)$. As composições percentual e química das dietas experimentais são apresentadas na Tabela 1.

Para a realização deste estudo, foram utilizados 20 coelhos da raça Nova Zelândia Branco, desmamados aos 40 dias, alojados em gaiolas individuais de metabolismo, providas de comedouros do tipo pote de argila e bebedouros tipo chupeta.

O período pré-experimental foi de sete dias, visando à adaptação dos animais às instalações, assim como a adequação do fornecimento das dietas e da coleta de fezes. O período experimental teve duração de sete dias, contados a partir do último dia do período préexperimental, no qual foram obtidas amostras diárias, perfazendo um total de 14 dias, sendo os animais pesados ao início e ao final do período experimental.

As amostras das rações experimentais foram acondicionadas em sacos plásticos identificados e guardados, de forma a obter-se uma amostra composta de cada tratamento. Posteriormente, foram moídas em moinho tipo "bola" e analisadas quanto à composição química.

Para as determinações químicas das fezes, o total produzido de cada animal foi coletado diariamente, pesado, acondicionado em sacos plásticos identificados e armazenados em freezer $\left(-10^{\circ} \mathrm{C}\right)$. Após a última coleta, as fezes foram descongeladas e misturadas criteriosamente, para se obter uma amostra composta, a qual foi submetida à pré-secagem em estufa de ventilação forçada a $65^{\circ} \mathrm{C}$, por 72 horas, e posteriormente moídas para realização das análises pertinentes.

Nas análises químicas das rações e das fezes, determinaram-se os teores de matéria seca (MS), em estufa a $105^{\circ} \mathrm{C}$; proteína bruta (PB), pelo método semimicro Kjeldahl; energia bruta (EB), utilizando-se a bomba calorimétrica PARR; extrato etéreo (EE), matéria mineral $(\mathrm{MM})$, fibra em detergente neutro (FDN) e fibra em detergente ácido (FDA), conforme metodologia descrita por SILVA (1990). A determinação do amido foi realizada pela metodologia da hidrólise ácida segundo a ASSOCIATION OFFICIAL ANALYTICAL CHEMISTRY - AOAC (1970).

O delineamento experimental utilizado foi o inteiramente casualizado, com quatro tratamentos e cinco repetições, sendo cada unidade experimental constituída por um animal, com base em PIMENTEL GOMES (1987). Os dados experimentais foram submetidos a análises de variância e regressão polinomial, contidas no programa de análises estatísticas ESTAT, desenvolvido pelo Departamento de Ciências Exatas da FCAVJ - UNESP.

\section{Resultados e Discussão}

Os valores de digestibilidade aparente dos nutrientes das dietas experimentais são apresentados na Tabela 2, na qual se observa que o melhor valor de digestibilidade da matéria seca $(65,03 \%)$ foi obtido com o maior nível de amido dietético (38\%), constatando-se, pela análise da Figura 1, efeito linear crescente $(\mathrm{P}<0,01)$ na digestibilidade total, sugerindo que os coelhos foram eficientes em utilizar o amido de milho, à medida que se elevou a sua participação dietética. A equação de regressão para digestibilidade da matéria seca $(\hat{Y}=56,63814+0,215192 X)$ demonstrou aumento de, aproximadamente, $0,21 \%$, para cada aumento de $1 \%$ no nível de amido.

Infere-se que a atividade amilásica dos coelhos às 7 semanas de idade já estava desenvolvida, em 
Rev. bras. zootec.

Tabela 1 - Composição percentual e química das rações experimentais

Table 1 - Chemical and percentage composition of the experimental diets

\begin{tabular}{|c|c|c|c|c|}
\hline \multirow[t]{2}{*}{$\begin{array}{l}\text { Ingredientes } \\
\text { Ingredients }\end{array}$} & \multicolumn{4}{|c|}{$\begin{array}{l}\text { Tratamentos } \\
\text { Treatments }\end{array}$} \\
\hline & $\begin{array}{c}\mathrm{T}_{1}(23 \% \text { de } \\
\text { amido })\end{array}$ & $\begin{array}{c}\mathrm{T}_{2}(28 \% \text { de } \\
\text { amido })\end{array}$ & $\begin{array}{c}\mathrm{T}_{3}(33 \% \text { de } \\
\text { amido })\end{array}$ & $\begin{array}{c}\mathrm{T}_{4}(38 \% \text { de } \\
\text { amido })\end{array}$ \\
\hline $\begin{array}{l}\text { Milho-grão } \\
\text { Corn grain }\end{array}$ & 18,00 & 18,00 & 18,00 & 18,00 \\
\hline $\begin{array}{l}\text { Farelo de soja } \\
\text { Soya bean meal }\end{array}$ & 18,00 & 18,00 & 18,00 & 18,00 \\
\hline $\begin{array}{l}\text { Farelo de trigo } \\
\text { Wheat meal }\end{array}$ & 15,00 & 15,00 & 15,00 & 15,00 \\
\hline $\begin{array}{l}\text { Feno de aveia } \\
\text { Oat hay }\end{array}$ & 15,00 & 15,00 & 15,00 & 15,00 \\
\hline $\begin{array}{l}\text { Casca de arroz } \\
\text { Rice hulls }\end{array}$ & 11,00 & 11,00 & 11,00 & 11,00 \\
\hline $\begin{array}{l}\text { Óleo de soja } \\
\text { Soybean }\end{array}$ & 8,13 & 5,17 & 2,23 & 0,00 \\
\hline $\begin{array}{l}\text { Amido de milho } \\
\text { Purified corn starch }\end{array}$ & 0,00 & 6,00 & 12,00 & 18,00 \\
\hline $\begin{array}{l}\text { Caulim } \\
\text { Inert }\end{array}$ & 9,87 & 6,83 & 3,77 & 0,00 \\
\hline $\begin{array}{l}\text { Sal } \\
\text { Salt }\end{array}$ & 0,50 & 0,50 & 0,50 & 0,50 \\
\hline $\begin{array}{l}\text { Mistura min. vit. }{ }^{1} \\
\text { Vit. min. supplement }\end{array}$ & 4,50 & 4,50 & 4,50 & 4,50 \\
\hline $\begin{array}{l}\text { Nutrientes } \\
\text { Nutrients }\end{array}$ & $(23 \%) \mathrm{T}_{1}$ & $(28 \%) \mathrm{T}_{2}$ & $(33 \%) \mathrm{T}_{3}$ & $(38 \%) \mathrm{T}_{4}$ \\
\hline $\begin{array}{l}\mathrm{MS}(\%) \\
D M\end{array}$ & 91,82 & 91,20 & 90,50 & 89,95 \\
\hline $\begin{array}{l}\mathrm{MM}(\%) \\
\text { Ash }\end{array}$ & 14,60 & 11,54 & 8,44 & 4,74 \\
\hline $\begin{array}{l}\mathrm{PB}(\%) \\
C P\end{array}$ & 14,92 & 14,88 & 14,89 & 14,86 \\
\hline $\begin{array}{l}\mathrm{FDN}(\%) \\
N D F\end{array}$ & 30,08 & 29,90 & 29,98 & 30,10 \\
\hline $\begin{array}{l}\mathrm{FDA}(\%) \\
A D F\end{array}$ & 17,86 & 17,85 & 17,86 & 17,88 \\
\hline $\begin{array}{l}\mathrm{EE}(\%) \\
\text { Fat }\end{array}$ & 9,63 & 6,68 & 3,73 & 2,21 \\
\hline $\begin{array}{l}\text { Amido (\%) } \\
\text { Starch }\end{array}$ & 22,99 & 27,97 & 32,95 & 37,93 \\
\hline $\begin{array}{l}\mathrm{EB}(\mathrm{kcal} / \mathrm{kg}) \\
G E\end{array}$ & 4001,2 & 4000,0 & 3998,8 & 4039,0 \\
\hline
\end{tabular}

concordância com os resultados observados por PARIGI-BINI et al. (1990), que também verificaram elevação na digestibilidade da matéria seca, de 58,5 para $60,5 \%$, à medida que se elevaram os níveis de amido das dietas de 17 para $25 \%$, e BLAS et al. (1990), que encontraram maior valor de digestibilidade da matéria seca com dietas que possuíam alta relação amido/fibra, no caso, com 25,6\% de amido (milho grão) e 17,3\% FDA (alfafa), sendo observados valores de 65,2 e $66,4 \%$, com 8 e 11 semanas de idade, respectivamente.

Os coeficientes de digestibilidade aparente da matéria orgânica são apresentados na Tabela 2, na qual se observa que o maior valor $(80,68 \%)$ foi alcançado com o maior nível de amido dietético (38\%), contatando-se, pela análise da Figura 2, efeito linear crescente $(\mathrm{P}<0,01)$ na digestibilidade da matéria orgânica, semelhantemente à matéria seca. A inclusão de quantidades elevadas de amido de milho nas rações demonstraram efeito direto sobre a 
ARRUDA et al.

Tabela 2 - Coeficientes de digestibilidade aparente das rações experimentais

Table 2 - Coefficients of the apparent digestibility coeficients of the experimental diets

\begin{tabular}{|c|c|c|c|c|c|}
\hline \multirow[t]{2}{*}{$\begin{array}{l}\text { Coeficiente dig. nutrientes } \\
\text { Coefficient of nutrients digestibility }\end{array}$} & \multicolumn{5}{|c|}{$\begin{array}{c}\text { Tratamentos } \\
\text { Treatments }\end{array}$} \\
\hline & $\begin{array}{c}\mathrm{T}_{1}(23 \% \\
\text { de amido })\end{array}$ & $\begin{array}{c}\mathrm{T}_{2}(28 \% \\
\text { de amido })\end{array}$ & $\begin{array}{c}\mathrm{T}_{3}(33 \% \\
\text { de amido) }\end{array}$ & $\begin{array}{c}\mathrm{T}_{4}(38 \% \\
\text { de amido) }\end{array}$ & $\mathrm{CV}(\%)$ \\
\hline $\begin{array}{l}\mathrm{CDMS}^{1}(\%) \\
C D D M\end{array}$ & 61,79 & 62,46 & 63,50 & 65,03 & $(2,28)$ \\
\hline $\begin{array}{l}\mathrm{CDMO}^{1}(\%) \\
\text { CDOM }\end{array}$ & 77,31 & 78,20 & 80,27 & 80,68 & $(1,62)$ \\
\hline $\begin{array}{l}\operatorname{CDPB}(\%) \\
C D C P\end{array}$ & 85,63 & 85,99 & 86,49 & 84,63 & $(1,69)$ \\
\hline $\begin{array}{l}\text { CDFDA }(\%) \\
C D A D F\end{array}$ & 21,37 & 21,64 & 23,17 & 23,94 & $(16,90)$ \\
\hline $\begin{array}{l}\mathrm{CDFDN}^{1}(\%) \\
C D N D F\end{array}$ & 30,72 & 32,83 & 35,77 & 36,65 & $(7,08)$ \\
\hline $\begin{array}{l}\operatorname{CDEE}^{1}(\%) \\
C D E E\end{array}$ & 89,46 & 86,25 & 81,74 & 76,96 & $(3,01)$ \\
\hline $\begin{array}{l}\operatorname{CDEB}(\%) \\
C D G E\end{array}$ & 65,20 & 65,32 & 66,16 & 65,05 & $(1,99)$ \\
\hline $\begin{array}{l}\text { CDAmido }^{1}(\%) \\
C D \text { starch }\end{array}$ & 74,35 & 78,74 & 84,50 & 87,26 & $(3,91)$ \\
\hline
\end{tabular}

1 Efeito linear $(\mathrm{P}<0,01)$.

Linear effect $(P<.01)$.

Amido (starch).

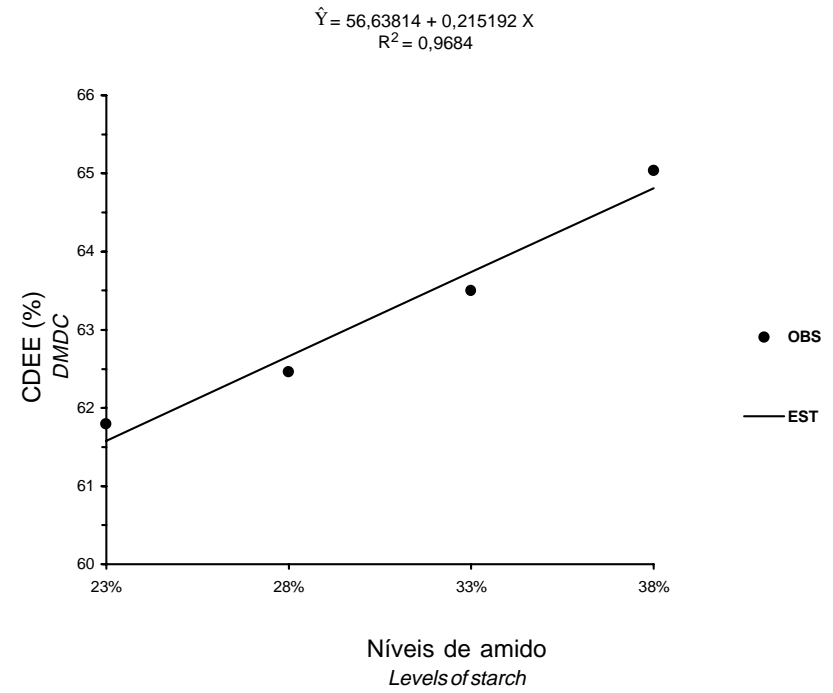

Figura 1 - Coeficientes de digestibilidade da matéria seca (COMD) observados com coelhos alimentados com diferentes níveis de amido dietético.

Figure 1 - Coefficients of dry matter digestibility (DMDC) for rabbits fed different dietary starch levels.

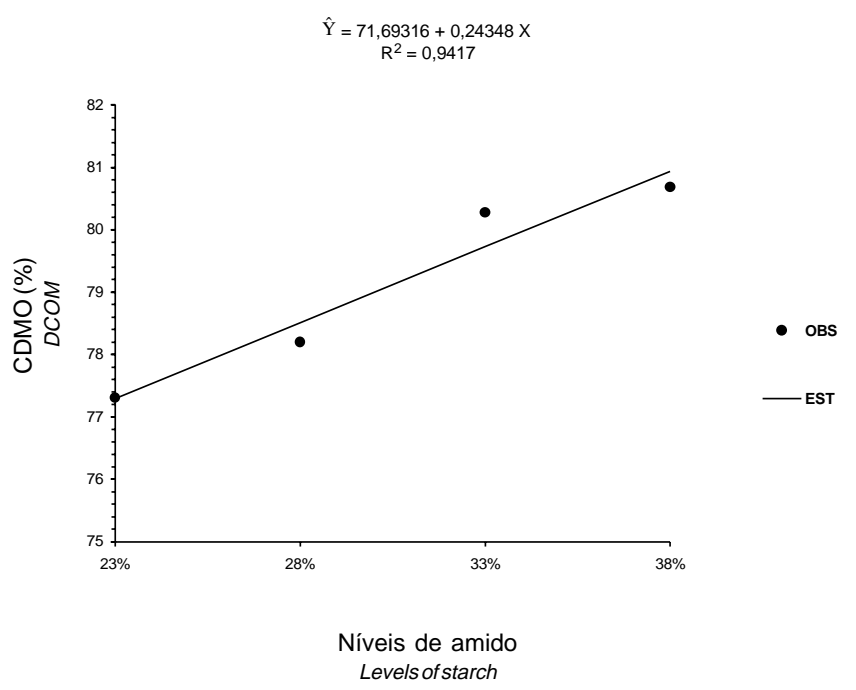

Figura 2 - Coeficientes de digestibilidade da matéria orgânica (CDMO) observados com coelhos alimentados com diferentes níveis de amido dietético.

Figure 2 - Coefficients of organic matter digestibility (COMD) for rabbits fed different dietary starch levels. 
digestibilidade total, ao incrementar a relação amido/ fibra na fração orgânica dietética, em concordância com LEBAS (1992).

A equação de regressão para digestibilidade da matéria orgânica ( $\hat{Y}=71,69316+0,24348 X)$ mostrou aumento de, aproximadamente, $0,24 \%$ para cada $1 \%$ de aumento no nível de amido. Os dados obtidos foram superiores aos observados por VILLAMIDE e DE BLAS (1991), que, ao avaliarem dietas com, aproximadamente, $23 \%$ de amido (milho grão), observaram digestibilidade média da matéria orgânica em torno de $60 \%$, e também superiores aos resultados obtidos por GIDENNE e PEREZ (1993b), que, ao fornecerem dietas contendo $25,6 \%$ amido (amido de milho purificado) e $29,2 \%$ amido (milho grão) como fonte de energia para coelhos em crescimento, observaram digestibilidade média em torno de 67 e $71 \%$, respectivamente.

Por outro lado, não houve efeito significativo sobre a digestibilidade aparente da proteína bruta, indicando que não houve influência dos níveis de amido dietéticos sobre a digestibilidade da fração protéica das dietas, como demonstrado pelos valores da Tabela 2. A relação energia/proteína, a fonte protéica, a qualidade e a quantidade de fibra similares entre os tratamentos, possivelmente, foram responsáveis pelas pequenas amplitudes observadas, em concordância com DE BLAS (1984) e CHEEKE (1987). De acordo com os dados de digestibilidade, os tratamentos apresentaram em torno de 12,77; 12,85; 12,95; e 12,57\% PD para as dietas contendo níveis de $23,28,33$ e $38 \%$ de amido total, respectivamente.

A análise de variância também não revelou significância para os coeficientes de digestibilidade aparente da energia bruta, indicando que o balanceamento do conteúdo energético com amido de milho e óleo de soja foi eficiente em manter os tratamentos isocalóricos, como demonstrado pelos valores da Tabela 2. De acordo com os dados de digestibilidade, os tratamentos apresentaram cerca de 2608, 2613, 2646 e $2628 \mathrm{kcal}$ ED/kg MS para as dietas contendo níveis de 23, 28, 33 e 38\% de amido, respectivamente.

Os valores de digestibilidade aparente do extrato etéreo das dietas encontram-se na Tabela 2 , na qual se constata que o maior valor $(89,46 \%)$ foi alcançado com o maiornível de extrato etéreo (Tabela 1), verificando-se, pela análise da Figura 3, efeito linear decrescente sobre a digestibilidade da gordura $(\mathrm{P}<0,01)$, com a elevação dos níveis de amido dietético. A equação de regressão para digestibilidade do extrato etéreo ( $\hat{Y}=109,2443-0,840604 X)$ apresentou redução de, aproximadamente, $0,84 \%$ para cada $1 \%$ de amido adicionado na dieta em substituição ao óleo de soja.

Os resultados sugerem que os maiores níveis de adição de óleo ou a elevação do extrato etéreo nas rações foram responsáveis pelos maiores coeficientes de digestibilidade, visto que a gordura vegetal possui alta digestibilidade para coelhos. De acordo com DE BLAS (1984) e CHEEKE (1987), a maior presença de gordura na digesta intestinal estimula a secreção de sais biliares para emulsionar e solubilizar os lipídios, favorecendo a atividade da lipase pancreática, assim como o aumento na reabsorção de bílis e circulação enterohepática. Os valores de CDEE observados neste trabalho estão de acordo com os observados por RAHARJO et al. (1988), os quais, ao avaliarem uma dieta contendo 27,0 e $2,1 \%$ e outra com 18,0 e $9,6 \%$ de amido e extrato etéreo, respectivamente, verificaram que a digestibilidade da gordura se situou em 72,06 e $84,89 \%$ para a primeira e segunda dietas.

Os valores de digestibilidade aparente do amido encontram-se na Tabela 2 , na qual se nota que o melhor valor $(87,26 \%)$ foi obtido com o maior nível de amido dietético (38\%), observando-se, pela análise da Figura 4, efeito linear crescente na digestibilidade do amido total $(\mathrm{P}<0,01)$, com a elevação dos níveis dietéticos, sugerindo que a atividade amilásica nos coelhos estava elevada e capacitada para permitir a digestão de grandes quantidades de amido.

A equação de regressão para digestibilidade do amido ( $\hat{Y}=54,08753+0,889376 \mathrm{X})$ sugeriu aumento de, aproximadamente, $0,89 \%$ para cada $1 \%$ de amido dietético. Segundo LLEONART (1980), o tipo de alimento pode influenciar a atividade secretória pancreática, com a finalidade de maximizar a digestão e absorção do nutrientes, por intermédio de quimiorreceptores duodenais, visto que a quantidade e a composição da digesta que chega ao duodeno são, provavelmente, os principais determinantes para o volume e a composição do suco pancreático. Assim, a quantidade de amido dietético pode ter influenciado a quantidade de amilase secretada e a atividade das sacaridases nas microvilosidades intestinais.

Adicionalmente, considerando-se a característica do amido de cereais em possuir maior proporção de amilopectina que amilose (GREENWOOD, 1970) e o fato de as propriedades estruturais do grânulo de amido influenciarem a taxa de hidrólise pela amilase pancreática de coelhos (LEE et al., 1985; GIDENNE e PEREZ, 1993a), pressupõe-se que a maior proporção de amido de milho em relação ao milho grão pode ter sido determinante para a relativa eficiência diges- 
774

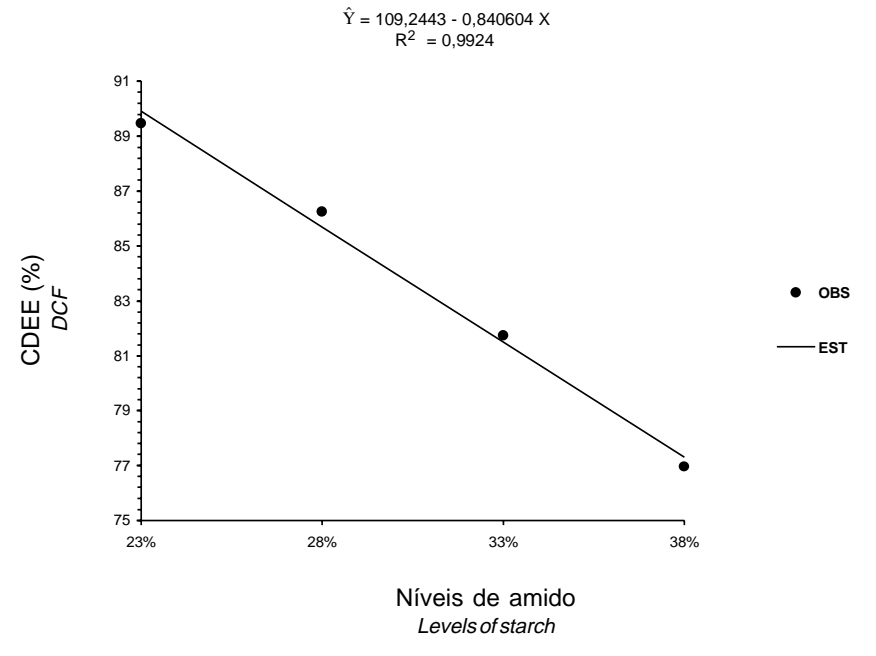

Figura 3 - Coeficientes de digestibilidade do extrato etéreo (CDEE) obtidos com coelhos alimentados com diferentes níveis de amido dietético.

Figure 3 - Coefficients of ether extract digestibility (CEED) for rabbits fed different dietary starch levels. tiva observada neste estudo.

No entanto, certa proporção do amido dietético foi fornecida por alimentos fibrosos ou não-amiláceos (Tabela 1), fator causal para os valores de digestibilidade situarem-se abaixo de $90 \%$, provavelmente em virtude de o método da hidrólise ácida superestimar o teor de amido nestes alimentos e, conseqüentemente, nas fezes. Assim, os valores obtidos neste estudo são inferiores aos observados com a mensuração pela hidrólise enzimática feita por BLAS et al. (1990), que, ao avaliarem dietas contendo 25,6\% de amido (milho), verificaram digestibilidade média entre 94,1 e $95,6 \%$, e aos resultados obtidos por GIDENNE e PEREZ (1993b), que, ao avaliarem dietas contendo $25,6 \%$ (purificado) e 29,2\% (grão) de amido total, observaram coeficientes de digestibilidade em torno de 99,7 e $99,0 \%$, respectivamente.

A análise de variância não revelou significância para os coeficientes de digestibilidade da fibra em detergente ácido, indicando que não houve influência significativa dos níveis de amido dietéticos sobre a digestibilidade da fração lignocelulose das rações. Os valores médios de digestibilidade aparente apresentam-se na Tabela 2 , na qual se constata aproveitamento similar desta fração mais lignificada para os diferentes níveis de amido das rações, justificável pela peculiar capacidade de separação e excreção da fibra de menor

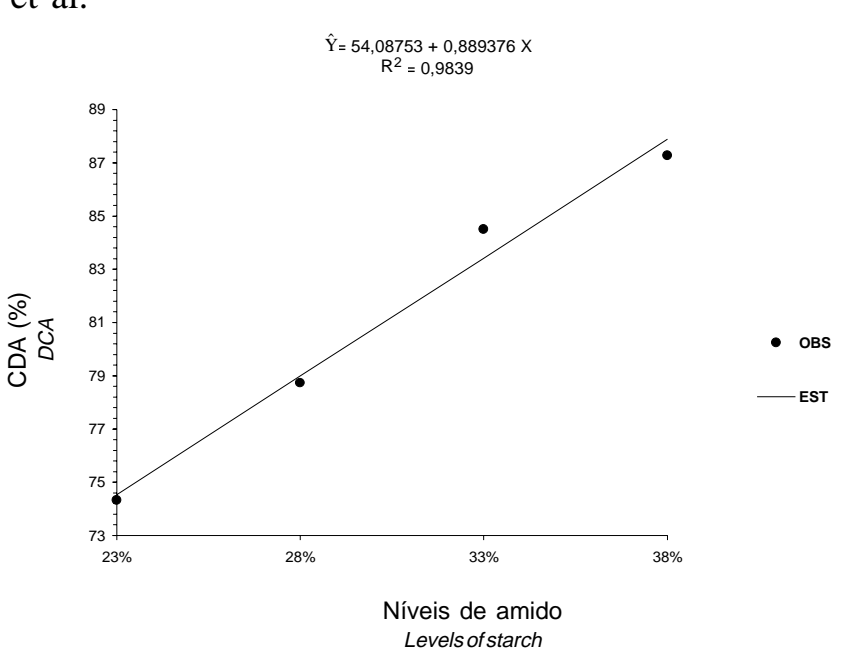

Figura 4 - Coeficientes de digestibilidade do amido (CDA) obtidos com coelhos submetidos alimentados com diferentes níveis de amido dietético.

Figure 4 - Coefficients of starch digestibility (CSD) for rabbits fed different dietary starch levels.

degradabilidade no ceco-cólon dos coelhos (LEBAS, 1992).

Os valores de digestibilidade aparente da fibra em detergente neutro obtidos com as dietas experimentais encontram-se na Tabela 2 , na qual se verifica que o melhor valor $(36,65 \%)$ foi obtido com o maior nível de amido (38\%), verificando-se, pela análise da Figura 5, efeito linear crescente sobre a digestibilidade da fração fibrosa $(P<0,01)$, com o aumento nos níveis de amido dietético. A equação de regressão para digestibilidade da fibra em detergente neutro ( $\hat{Y}=21,3548+0,4144 \mathrm{X})$ demonstrou aumento de, aproximadamente, $0,41 \%$ para cada $1 \%$ de aumento no nível de amido. De acordo com GIDENNE (1996), isto pode ser reflexo da energia suplementar fornecida por substrato mais equilibrado qualitativamente, sem promover efeito competitivo sobre a microbiota, melhorando a atividade fermentativa cecal. Porém, certa competição por substrato pode ter ocorrido, devido à maior quantidade relativa de amido indigerido, possivelmente oriundo dos grãos de milho, quando associado aos maiores níveis de óleo dietético, os quais podem ter sido suficientes para deprimir a degradação das frações celulose e hemicelulose no cecocólon, pois maiores níveis de gordura indigerida podem proporcionar envolvimento das partículas, dificultando a aderência das bactérias para a atividade fibrolítica em potencial. 


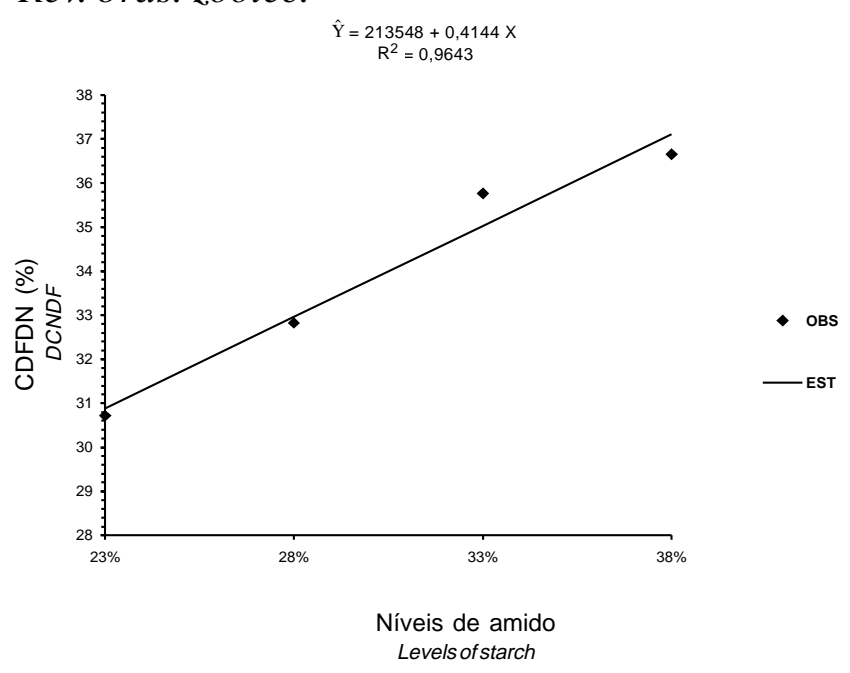

Figura 5 - Coeficientes de digestibilidade da fibra em detergente neutro (CDFDN) observados com coelhos alimentados com diferentes níveis de amido dietético.

Figure 5 - Coefficients of neutral detergent fiber digestibility (CNDFD) observed in rabbits fed different dietary starch levels.

\section{Conclusões}

A dieta experimental com $38 \%$ de amido foi a que proporcionou os melhores valores de digestibilidade aparente da matéria seca, matéria orgânica, fibra em detergente neutro e amido, evidenciando a otimização da capacidade dos coelhos em digerir enzimaticamente o amido de milho e sua importância para a degradação da fibra no intestino grosso. Por outro lado, o nível mínimo adequado de fibra, o processamento para a obtenção do amido de milho e a peletização, provavelmente, foram determinantes para evitar a ocorrência de diarréias e potencializar a digestibilidade, à medida que se elevou a participação da fração amilácea nas dietas.

\section{Referências Bibliográficas}

ASSOCIATION OFFICIAL ANALYTICAL CHEMISTRY AOAC. 1970. Official methods of analysis.11 ed. Washington DC. $1015 \mathrm{p}$.

BLAS, E., FANDOS, J.C., CERVERA, C. et.al. 1990. Effet de la nature et du taux d'amidon sur l'utilisation digestive de la ration chez le lapin, au cours de la croissance.J. Rec. Cunicole, 5(50):1-9.

CHEEKE, P.R., PATTON, N.M. 1980. Carbohydrate-overload of the hindgut: a probable cause of enteritis. J. Appl. Rabbit Res., 3(1):20-23.

CHEEKE, P.R. 1987. Rabbitfeeding and nutrition. 3.ed. Oregon: Academic Press. 380p.
CHEEKE, P.R. 1989. Rabbit nutrition: A quiet growth area with great potential. Biotechnology in the feed industry, Alltech Publications, p.249-260

DE BLAS, C. 1984. Alimentación del conejo. 3.ed. Madrid, Mundi-Prensa. 175p.

DE BLAS, C. 1991. Alimentazione in svezzamento e patologia digestiva. Bologna, Riv. Coniglicoltura, 28(7):13-21.

GIDENNE, T., PEREZ, J.M. 1993a. Effect of dietary starch origin on digestion in the rabbit. 1. Digestibility measurements from weaning to slaughter. Anim. Feed Sci. Tech., 42(3-4):237-247.

GIDENNE, T., PEREZ, J.M. 1993b. Effect of dietary starch origin on digestion in the rabbit. 2. Starch hydrolysis in the small intestine, cell wall degradation and rate of passage measurements. Anim. Feed Sci. Tech., 42(3-4):249-257.

GIDENNE, T. Nutritional and ontogenic factors affecting rabbit caeco-colic digestive physiology. In: WORLD RABBIT CONGRESS, Toulouse, 6, 1996. Proceedings... Toulouse: World Rabbit Science Association, vol.1, p.13-28, 1996.

GREENWOOD, C.T. 1970. Starch and glycogen. In: PIGMAN, W., HORTON, D. The carbohydrates. New York, Academic Press, 1 ed., p. 471-509.

LEBAS, F. 1992. Alimentazione pratica dei conigli all'ingrasso. Riv. Coniglicoltura, 29(7/8):17-29.

LEE, P.C., BROOKS, S.P., KIM, O. et.al. 1985. Digestibility of native and modified starches: in vitro studies with human and rabbit pancreatic amylases and in vivo studies in rabbits. J. Nutr.,(115):93-103.

LLEONART, F.R. 1980. Tratado de Cunicultura. Anatomía y fisiología del aparato digestivo. Barcelona, Real Escuela Oficial y Superior de Avicultura, vol.1, p.61-84.

MORISSE, J.P. 1986. Incidenza delle turbe digestive e delle enteropatie sulla mortalitá del coniglio. Riv. Conigliocoltura, 23(2):28-35.

NATIONAL RESEARCH COUNCIL - NRC 1977. Nutrients requirements of domestic animals: nutrient requirements of rabbits. 2.ed. Washington D.C. 30p.

PARIGI-BINI, R., XICCATO, G., CINETTO, M. 1990. Influenza del contenuto di amido alimentare sulla produttivitá, sulla digeribilitá e sulla composizione corporea di conigli in accrescimento. Zoot. Nutr. Anim., 16(4):271-282.

PIMENTEL GOMES, F.P. 1987. Curso de estatística experimental. Piracicaba: ESALQ/USP. 467p.

RAHARJO, Y.C., CHEEKE, P.R., PATTON, N.M. 1988. Evaluation of tropical forages and rice by products as rabbit feeds. J. Appl. Rabbit Res., 11(3):201-211.

SILVA, D.J. 1990. Análise de alimentos (métodos químicos e biológicos). Viçosa: UFV. 166p.

VILLAMIDE, M.J., DE BLAS, C. 1991 Nutritive value of cereal grains for rabbits. J. Appl. Rabbit Res., 14(2):144-147.

Recebido em: 07/07/99

Aceito em: 13/10/99 